\title{
Etomidate alleviates cardiac dysfunction, fibrosis and oxidative stress in rats with myocardial ischemic reperfusion injury
}

\author{
Dili Xie ${ }^{1 \#}$, Min $\mathrm{Li}^{2 \#}$, Kang Yu ${ }^{3}$ Hua Lu ${ }^{4 \wedge}$, Yong Chen ${ }^{3 \wedge}$ \\ ${ }^{1}$ Department of Geriatric Cardiology, Sichuan Academy of Medical Science \& Sichuan Provincial People's Hospital, Chengdu, China; ${ }^{2}$ Department \\ of Geriatric ICU, Sichuan Academy of Medical Science \& Sichuan Provincial People's Hospital, Chengdu, China; ${ }^{3}$ Department of Cardiology, West \\ China Hospital, Sichuan University, Chengdu, China; ${ }^{4}$ Anesthesia Operation Center, Sichuan Academy of Medical Science \& Sichuan Provincial \\ People's Hospital, Chengdu, China \\ Contributions: (I) Conception and design: Y Chen, H Lu; (II) Administrative support: D Xie, M Li; (III) Provision of study materials or patients: B \\ Cheng, H Lu; (IV) Collection and assembly of data: D Xie, M Li, Y Kang; (V) Data analysis and interpretation: Y Chen, H Lu; (VI) Manuscript \\ writing: All authors; (VII) Final approval of manuscript: All authors. \\ \#These authors contributed equally to this work. \\ Correspondence to: Hua Lu. Anesthesia Operation Center, Sichuan Academy of Medical Science \& Sichuan Provincial People's Hospital, Chengdu, \\ China. Email: 349903364@qq.com; Yong Chen. Department of Cardiology, West China Hospital, Chengdu, China. Email: 1809009521@qq.com.
}

Background: Etomidate has been shown to reduce ischemia/reperfusion (I/R) injury in several tissues. Here we aimed to investigate the protective effects of etomidate on I/R injury in Sprague-Dawley (SD) rats. Methods: Thirty rats were randomly divided into 5 groups and pretreated with saline or $0.5 / 1 / 2 \mathrm{mg} / \mathrm{kg}$ etomidate. I/R injury was induced in all groups except the sham control group. After administration with saline or $0.5 / 1 / 2 \mathrm{mg} / \mathrm{kg}$ etomidate daily for another 27 days, rats were sacrificed and the effects of etomidate were analyzed.

Results: Treatment with etomidate dose dependently improved echocardiography indexes, ameliorated myocardial histological alterations and reduced serum creatine kinase isoenzyme (CK-MB), myoglobin $(\mathrm{Mb})$ and troponin I (cTnl) levels. Fibrosis markers transforming growth factor beta (TGF- $\beta$ ), alpha-smooth muscle actin ( $\alpha$-SMA) and fibronectin was decreased with etomidate treatment. Etomidate also decreased oxidative stress and inflammation in rats, indicated by increased superoxide dismutase (SOD) and glutathione (GSH), and reduced malondialdehyde (MDA) in myocardial tissues, as well as decreased inducible NO synthase (iNOS) and increased interleukin (IL)-10 in both serum and myocardial tissues.

Conclusions: Altogether, we showed that etomidate alleviated I/R injury in rats through reduced cardiac dysfunction, fibrosis and oxidative stress. These results supported the protective role of etomidate to myocardial I/R injury.

Keywords: Etomidate; fibrosis; inflammation; myocardial I/R injury; oxidative stress

Submitted Jul 29, 2020. Accepted for publication Sep 11, 2020.

doi: 10.21037/atm-20-6015

View this article at: http://dx.doi.org/10.21037/atm-20-6015

\section{Introduction}

Ischemic heart disease (IHD) is one of the leading causes of death worldwide (1). IHD is predominantly caused by a rupture of atherosclerotic plaques in the coronary arteries.
In order to save the ischemic myocardium, coronary blood flow must be re-established. However, during this process, dramatic changes can occur to the mitochondrial permeability transition pore (mPTP) opening, generation of

^ ORCID: Hua Lu, 0000-0003-4005-9288; Yong Chen, 0000-0003-1882-2259. 
reactive oxygen species (ROS), bioavailability of nitric oxide (NO), intracellular distribution of $\mathrm{Ca}^{2+}$ and $\mathrm{Na}^{+}$, and $\mathrm{pH}$ (2). As a result, reperfusion itself actually leads to myocardial cell death and subsequent irreversible myocardial injury, known as ischemia-reperfusion (I/R) injury (3).

Myocardial protection by anesthetics is a fascinating phenomenon that has been extensively studied in various animal models. Several mechanisms have been elucidated, including the stimulation of a small amount of ROS, enhancement of endogenous antioxidants and the regulation of ion transport (2). Etomidate has been used clinically for the induction of anesthesia (4), and has been demonstrated to protect against $\mathrm{I} / \mathrm{R}$ injury in various organs across species. For example, etomidate alleviated spinal cord I/R injury induced by aortic occlusion in rabbits, mainly through reducing oxidative stress and rebalancing ion transport (5). Importantly, etomidate inhibited myocardial apoptosis and reduced the percentages of infarct/risk ratio, thus reducing $\mathrm{I} / \mathrm{R}$ injury in rabbit hearts (6). To elaborate on these previous findings, the present study independently evaluated etomidate for treating cardiac I/R injury in rats. Fibrosis, oxidative stress and inflammation were also investigated as the underlying mechanisms of action. We present the following article in accordance with the ARRIVE reporting checklist (available at http://dx.doi.org/10.21037/atm-206015).

\section{Methods}

\section{Animals}

The animal experimental protocol was approved by the Ethics Committee of Sichuan Academy of Medical Science \& Sichuan Provincial People's Hospital and applied according to Chinese National Guidelines (GB/T 3589220181). Eight-week-old male Sprague-Dawley (SD) rats weighing 250-260 g were purchased from the Experimental Animal Centre of Sichuan Academy of Medical Science \& Sichuan Provincial People's Hospital. The rats were housed in a conditioned environment $\left(22 \pm 1^{\circ} \mathrm{C}, 12 \mathrm{~h} \mathrm{light/darkness}\right.$ cycle, free access to food and water). After randomized, six rats were used as sham-operated controls, and 24 rats survived the surgery were assigned to ischemia-reperfusion (I/R) treatment. Eighteen of the I/R rats were pretreated with $0.5,1$ or $2 \mathrm{mg} / \mathrm{kg}$ of etomidate (Jiangsu Nhwa Pharmaceutical, Xuzhou, China), while the remaining 6 rats were injected with equivalent saline. All rats were anesthetized with an intraperitoneal injection of $3 \mathrm{~mL} / \mathrm{kg}$ of $10 \%$ chloral hydrate (Tianjin Kemiou Chemical Reagent Co, Ltd, Tianjin, China). The left coronary artery (LCA) of $\mathrm{I} / \mathrm{R}$ rats was ligated at the edge of the left atrial appendage for $50 \mathrm{~min}$ followed by reperfusion (7). The rats were then administered $0.5,1$ or $2 \mathrm{mg} / \mathrm{kg}$ of etomidate or equivalent saline for 27 days in accordance with pretreatment. Echocardiography was then performed, using a $15-\mathrm{MHz}$ linear array transducer (iE33 system, Philips medical systems), to test the left ventricle (LV) diastole and systole (8). The rats were then sacrificed, and blood and heart tissues were collected (8).

\section{Determination of cardiac marker enzymes in serum}

Serum was isolated from the blood samples by centrifugation $\left(3,000 \mathrm{rpm}, 4^{\circ} \mathrm{C}, 10 \mathrm{~min}\right)$. Creatine kinase $(\mathrm{CK})$ and creatine kinase isoenzymes (CK-MB) were measured using spectrophotometric kits according to the manufacturer's instructions, and were analyzed using an automatic biochemical analyzer (Hitachi, Japan).

\section{Hematoxylin and eosin staining}

Myocardial tissues were fixed in 4\% paraformaldehyde (Beyotime Biotechnology, Shanghai, China) overnight at $4{ }^{\circ} \mathrm{C}$. Tissues were then dehydrated in a series of ethanol and xylene solutions and embedded in paraffin. Sections of $5 \mu \mathrm{m}$ thickness were cut then deparaffinized. Hematoxylin and eosin (H\&E Staining Kit, Beyotime Biotechnology Co., Ltd, China) staining was performed according to the manufacturer's instructions. Sections were then observed under a light-field microscope.

\section{Enzyme linked immunosorbent assay (ELISA)}

Troponin I (ab246529, Abcam, Cambridge, UK), iNOS (RPA837Ra02, Cloud-Clone Corp., Wuhan, China) and IL-10 (SEA056Ra, Cloud-Clone Corp., Wuhan, China) ELISA kits were used to measure protein expression in rat serum in accordance with the manufacturer's instructions. The standard preparations were added to the first and second wells, followed by serial dilutions. Sample diluent and samples were added to each well at $37^{\circ} \mathrm{C}$ for $30 \mathrm{~min}$. After washing, secondary antibodies were added to each well at $37^{\circ} \mathrm{C}$ for $30 \mathrm{~min}$. After washing, chromogenic agents $\mathrm{A}$ and $\mathrm{B}$ were added to each well at $37^{\circ} \mathrm{C}$ in the dark for $15 \mathrm{~min}$. Termination solution was then added to each well. A microplate reader (Bio-Rad, USA) was used for detection. 
Sample concentrations were calculated according to the standard curve.

\section{Quantitative real-time polymerase chain reaction ( $q R T$ - PCR) analysis}

Total RNA was extracted from the myocardial samples using TRIzol reagent (Invitrogen, Carlsbad, CA, UK). Two $\mu g$ of total RNA from each sample was reverse-transcribed into cDNA. The qRT-PCR was performed using a SYBR Green PCR Reagent Kit (Applied Biosystems, Foster City, CA, USA) on an ABI Prism 7700 Sequence Detection System (PE Biosystems, Rotkreuz, Switzerland). The primers used were:

TGF- $\beta$ : forward 5 '-CTGG AAAG GGCT CAAC ACCT-3', reverse 5'-CTTC TCTG TGGA GCTG AAGC A-3'; $\alpha$-SMA: forward 5'-GGAG TGAT GGTT GGAA TGG-3', reverse 5'-ATGA TGCC GTGT TCTA TCG-3'; Fibronectin: forward 5'-GAAA GGCA ACCA GCAG AGTC-3', reverse 5'-CTGG AGTC AAGC CAGA CACA-3'; and GAPDH: forward 5'-TGCA CCAC CAAC TGCT TAG-3', reverse 5'-GATG CAGG GATG ATGT TC-3'. The mRNA levels were normalized to GAPDH mRNA levels.

\section{Western blotting}

Myocardial tissues were homogenized and RIPA lysis buffer was added (Beyotime Biotechnology, Shanghai, China). The Bradford assay was applied to test and balance protein concentrations. Samples were then separated by SDS-PAGE, and were transferred to PVDF membranes. Protein monoclonal antibodies were added for overnight incubation. After TBST rinsing, secondary antibodies were added for $1 \mathrm{~h}$ incubation. The proteins of interest were visualized using enhanced chemiluminescence reagents on a ChemiDoc XRS. Primary antibodies used were: TGF- $\beta$ (ab31013), $\alpha$-SMA (ab32575), fibronectin (ab32419), iNOS (ab213987), IL-10 (ab33471), GAPDH (ab181602) and all secondary antibodies were from Abcam (Cambridge, UK). Bands were analyzed using Image $\mathrm{J}$ software.

\section{Determination of superoxide dismutase (SOD), malondialdehyde (MDA) and glutatbione (GSH) in tissue}

Myocardial tissues were homogenized in saline to obtain $10 \%$ homogenates. The homogenates were centrifuged $\left(3,000 \mathrm{rpm}, 4{ }^{\circ} \mathrm{C}, 10 \mathrm{~min}\right)$, and the supernatants were collected for subsequent measurements. SOD and GSH levels in the tissues were determined before a Bradford assay was applied to test protein concentrations. For the MDA activity assay, the samples used were from western blotting experiments. An MDA testing working solution (Beyotime Biotechnology, Shanghai, China) was prepared, and optical density was analyzed under $532 \mathrm{~nm}$. For SOD measurement, the samples, WST-8/enzyme working solution, reaction initiating solution (Beyotime Biotechnology, Shanghai, China) and PBS were combined, incubated at $37{ }^{\circ} \mathrm{C}$ for $30 \mathrm{~min}$, and the optical density was analyzed under $450 \mathrm{~nm}$. For GSH measurement, total GSH working solution (Beyotime Biotechnology, Shanghai, China), S solution and samples were added and incubated for $5 \mathrm{~min}$. NADPH solution $(50 \mu \mathrm{L}, 0.5 \mathrm{mg} / \mathrm{mL})$ was added to each well and optical density at $412 \mathrm{~nm}$ was analyzed. SOD, MDA and GSH concentrations were calculated using standard curves (9).

\section{Statistics}

Data were analyzed using Statistical Package for the Social Science (SPSS, version 16.0) statistical analysis software. Data were shown as mean \pm standard error of mean (SEM), and analyzed using one-way analysis of variance (ANOVA) with the Student-Newman-Keuls post hoc test. $\mathrm{P}$ values below $0.05(\mathrm{P}<0.05)$ were considered statistically significant.

\section{Results}

\section{Etomidate recovered cardiac function in I/R rats}

Echocardiography was performed in rats that received I/R surgery and etomidate treatment. After treatment for a month, heart rate (HR, Figure $1 A), \mathrm{LV}$ systolic pressure (LVSP, Figure 1B), LV ejection fraction (LVEF, Figure 1C), and percent of fractional shortening (FS\%, Figure 1D) were all markedly reduced after I/R surgery. Treatment with etomidate dose dependently restored these indexes $\left({ }^{*} \mathrm{P}<0.05\right.$ versus control, ${ }^{\#} \mathrm{P}<0.05$ versus $\left.\mathrm{I} / \mathrm{R}\right)$. These results suggest that etomidate can alleviate myocardial I/R injury in rats.

\section{Etomidate mitigated myocardial injury in I/R rats}

Next, myocardial injury in rats was investigated. In H\&E staining of rat ischemic myocardial tissues, myocardial cells were abnormal, characterized by many necrotic cells, 
A

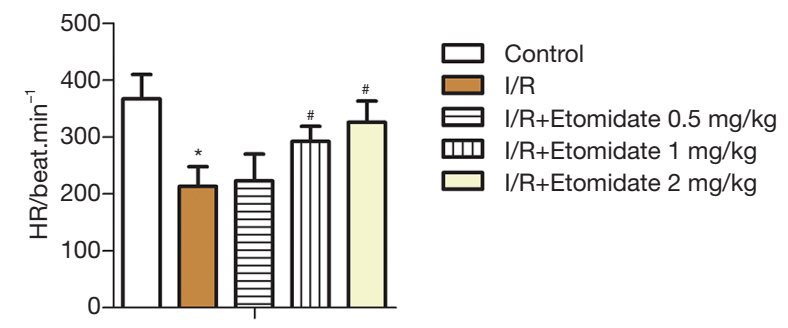

C

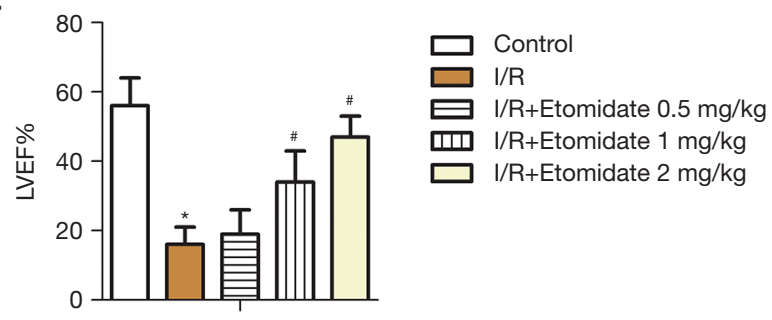

B
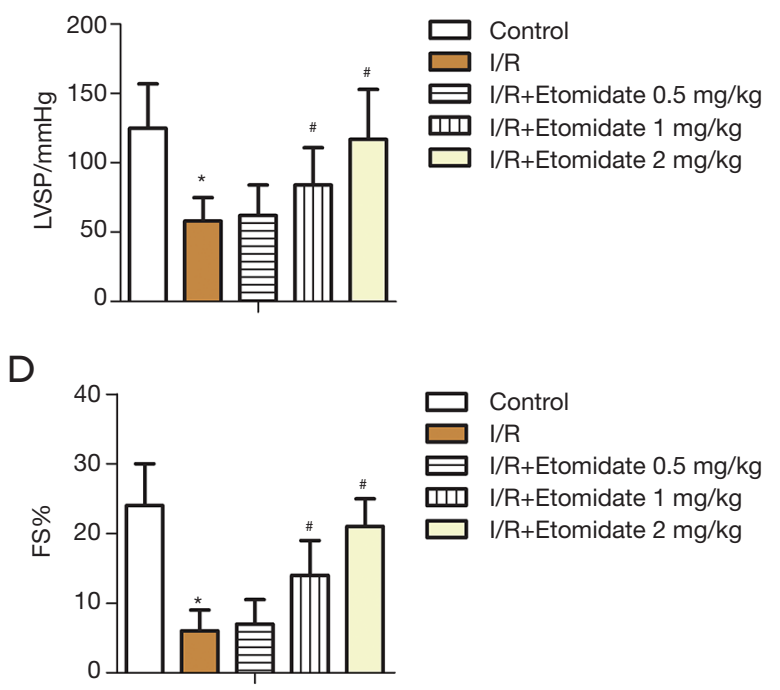

Figure $1 \mathrm{Effects}$ of etomidate on rat cardiac function. I/R rats were treated with the indicated doses of etomidate or saline for 28 days before echocardiography was performed. HR (A), LVSP (B), LVEF (C), and FS (D) were tested. N=6 for each group. *, $\mathrm{P}<0.05$ versus control; ", $\mathrm{P}<0.05$ versus I/R. FS, fractional shortening; HR, heart rate; I/R, ischemia/reperfusion; LVEF, left ventricle ejection fraction; LVSP, left ventricle systolic pressure.

nucleus lysis, shrinkage, myocardial fiber tears, and deep nuclear staining. These I/R induced effects, indicative of myocardial damage, were dose dependently mitigated with etomidate treatment (Figure 2A). Serum markers of myocardial damage were also tested. As expected, CK-MB, $\mathrm{MB}$ and troponin (cTnl) were all markedly elevated with I/R while dose dependently reduced with etomidate treatment (Figure $2 B, C, D,{ }^{*} \mathrm{P}<0.05$ versus control, ${ }^{\#} \mathrm{P}<0.05$ versus I/R). Fibrosis, oxidative stress, and inflammation were then investigated to preliminarily evaluate the mechanism of action of etomidate in $\mathrm{I} / \mathrm{R}$ rats.

\section{Etomidate reduced cardiac fibrosis in I/R rats}

Fibrosis markers including TGF- $\beta, \alpha$-SMA and fibronectin in rat heart tissues were tested. Both relative mRNA (Figure $3 A$ ) and protein (Figure $3 B$ ) expression of related genes were significantly induced with I/R surgery and dose dependently downregulated with etomidate treatment $\left({ }^{*} \mathrm{P}<0.05\right.$ versus control, ${ }^{\#} \mathrm{P}<0.05$ versus $\left.\mathrm{I} / \mathrm{R}\right)$.

\section{Etomidate inhibited cardiac oxidative stress in I/R rats}

Levels of SOD (Figure 4A) and GSH (Figure 4B) in myocardial tissues were significantly reduced with $\mathrm{I} / \mathrm{R}$ while dose dependently increased with etomidate treatment $\left({ }^{*} \mathrm{P}<0.05\right.$ versus control, ${ }^{*} \mathrm{P}<0.05$ versus $\mathrm{I} / \mathrm{R})$. MDA was markedly induced in $\mathrm{I} / \mathrm{R}$ rats and was dose dependently inhibited with etomidate treatment (Figure $4 C,{ }^{*} \mathrm{P}<0.05$ versus control, ${ }^{*} \mathrm{P}<0.05$ versus $\mathrm{I} / \mathrm{R}$ ). The results revealed that etomidate can reduce oxidative stress in $\mathrm{I} / \mathrm{R}$ rats.

\section{Etomidate decreased inflammation in I/R rats}

Finally, inflammation in I/R rats was tested. Serum iNOS was markedly induced in $\mathrm{I} / \mathrm{R}$ rats, which was reduced with etomidate treatment (Figure $5 A,{ }^{*} \mathrm{P}<0.05$ versus control, ${ }^{\text {\# }} \mathrm{P}<0.05$ versus $\left.\mathrm{I} / \mathrm{R}\right)$. Serum IL-10 was significantly induced in $\mathrm{I} / \mathrm{R}$ rats, which was further elevated with etomidate treatment (Figure $5 B,{ }^{*} \mathrm{P}<0.05$ versus control, ${ }^{*} \mathrm{P}<0.05$ versus $\mathrm{I} / \mathrm{R})$. Similarly, iNOS was induced in the myocardial tissues of I/R rats, which was inhibited with etomidate, while IL10 was induced in the myocardial tissues of $\mathrm{I} / \mathrm{R}$ rats and further increased with etomidate (Figure $5 C, D,{ }^{*} \mathrm{P}<0.05$ versus control, ${ }^{\#} \mathrm{P}<0.05$ versus $\left.\mathrm{I} / \mathrm{R}\right)$. These results suggest that inflammation in $\mathrm{I} / \mathrm{R}$ rats can be inhibited by etomidate treatment. 
A

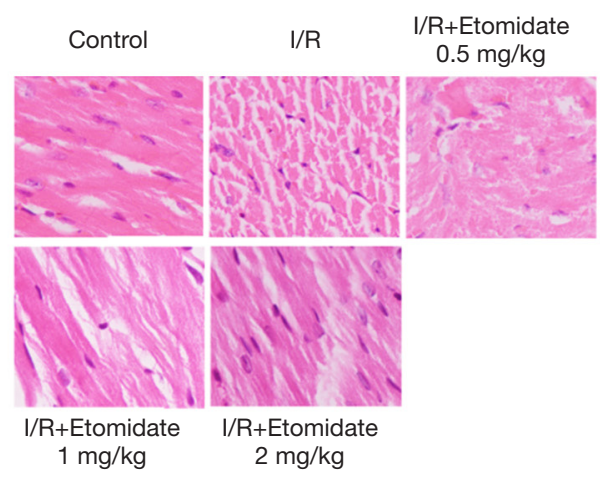

C

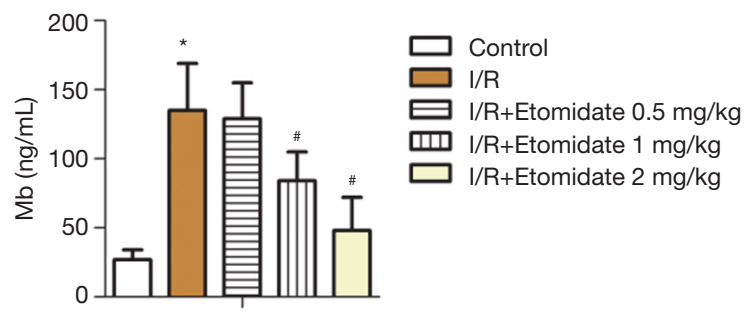

B

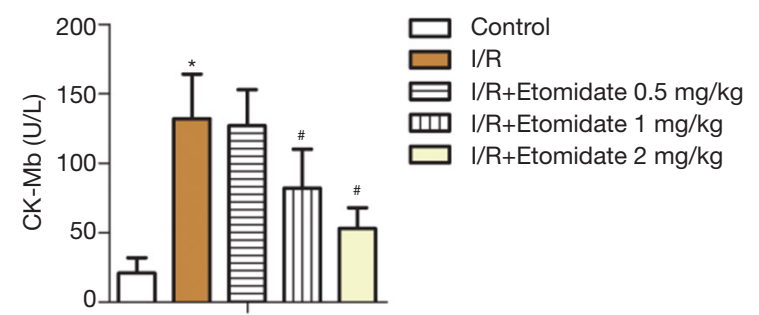

D

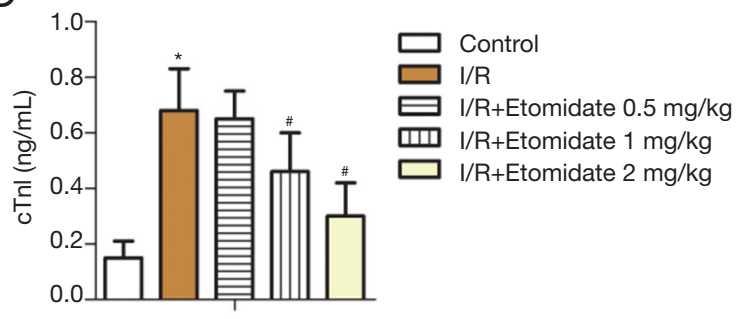

Figure 2 Effects of etomidate on rat myocardial injury. (A) HE staining of rat myocardial tissues observed under 200× scope. (B) CK-MB and (C) MB were detected using spectrophotometric kits. (D) Troponin (cTnl) was measured by ELISA. N=6 for each group. *, $\mathrm{P}<0.05$ versus control; ${ }^{\#}, \mathrm{P}<0.05$ versus $\mathrm{I} / \mathrm{R}$.

A

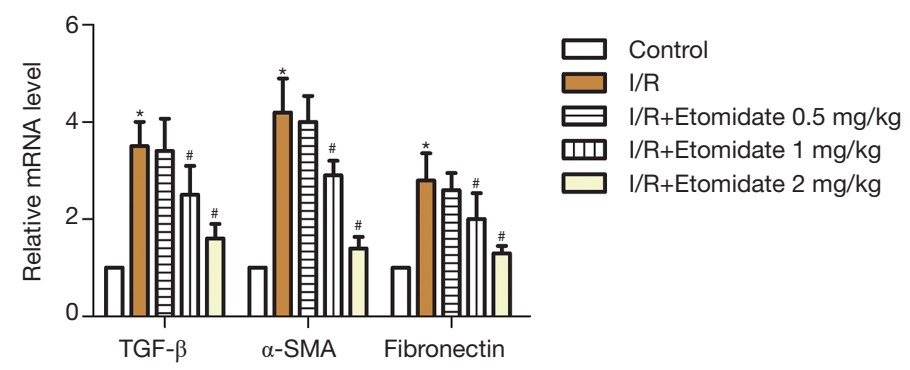

B
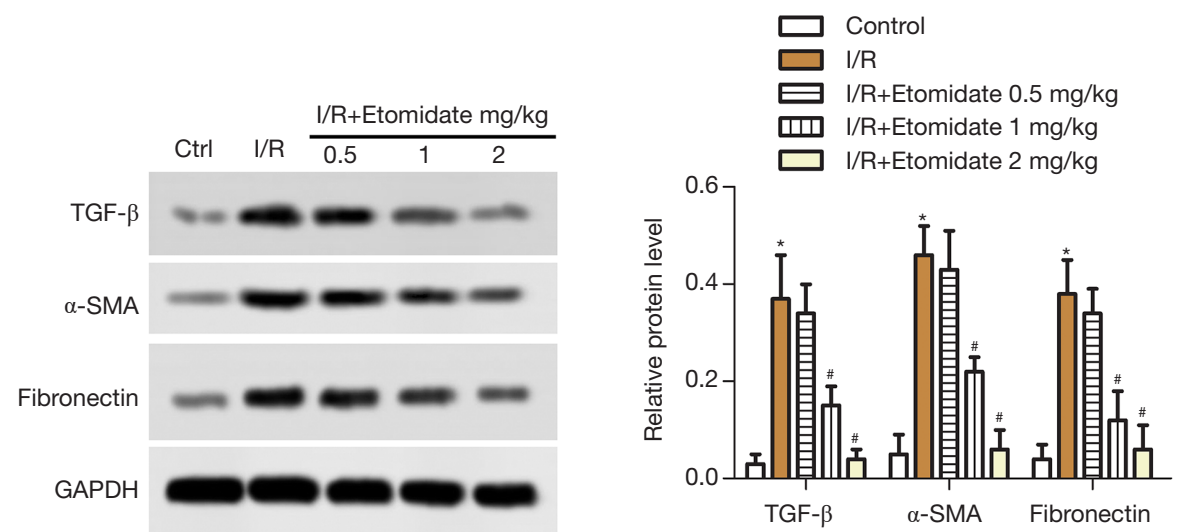

Figure 3 Effects of etomidate on fibrosis in rat myocardial tissues. (A) mRNA expression of TGF- $\beta, \alpha$-SMA and fibronectin in rat myocardial tissues. (B) Protein expression of TGF- $\beta, \alpha$-SMA and fibronectin was measured with western blotting. N=6 for each group. *, $\mathrm{P}<0.05$ versus control; ${ }^{~}, \mathrm{P}<0.05$ versus I/R. 
A

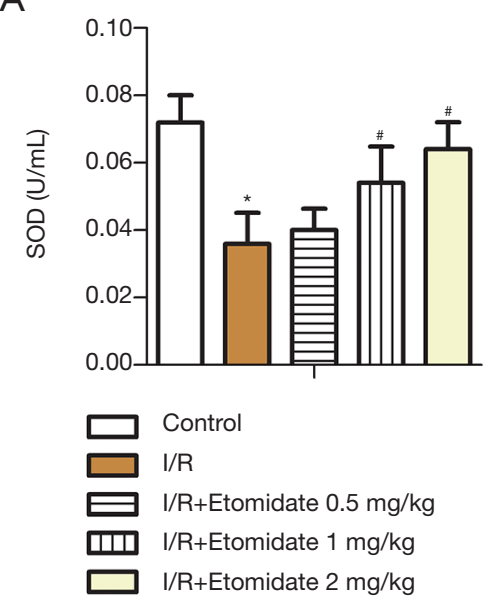

B

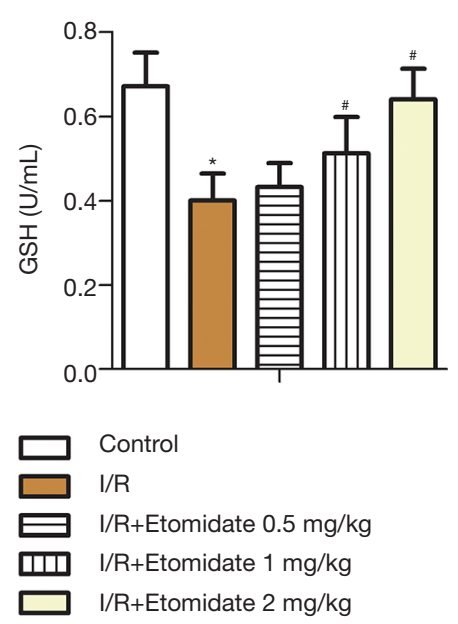

C

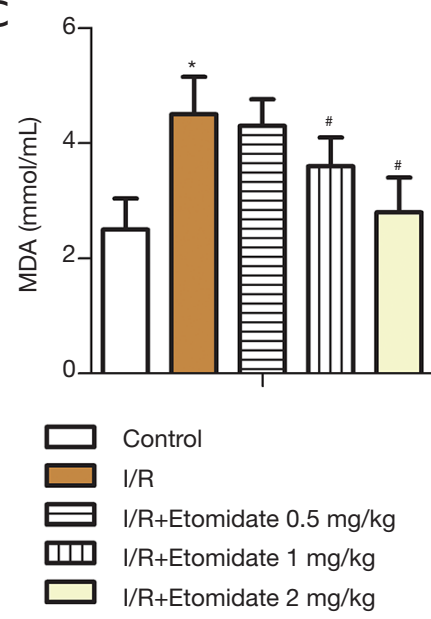

Figure 4 Effects of etomidate on oxidative stress in rat myocardial tissues. SOD (A), GSH (B), and MDA (C) activity levels in rat myocardial tissues were measured with related kits. $\mathrm{N}=6$ for each group. *, $\mathrm{P}<0.05$ versus control; ${ }^{*}, \mathrm{P}<0.05$ versus I/R.

A

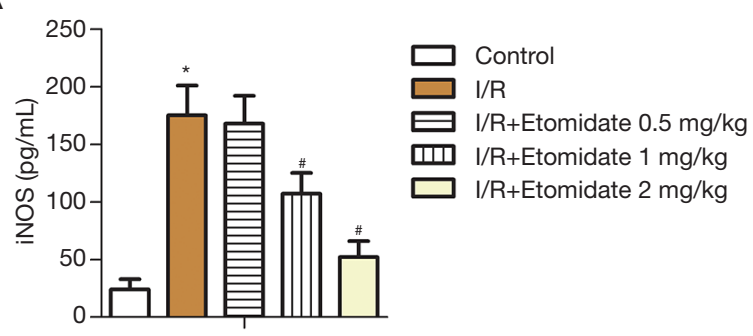

B

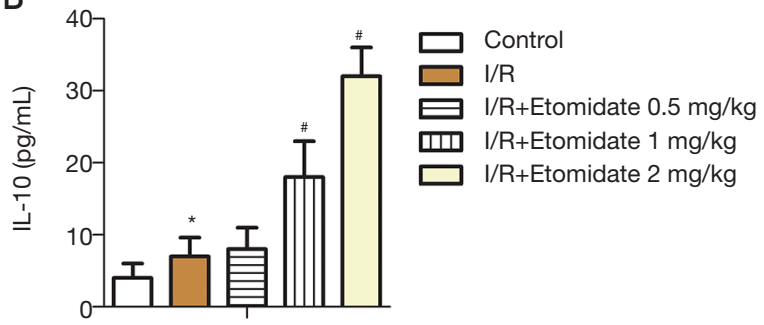

C

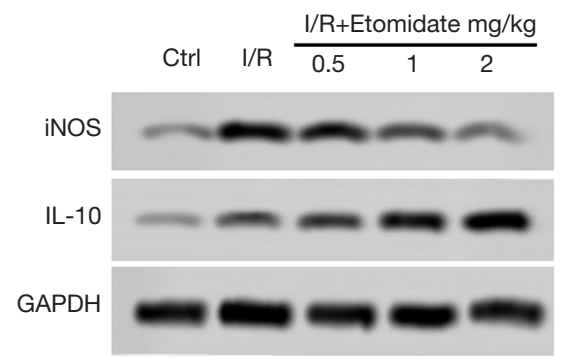

D

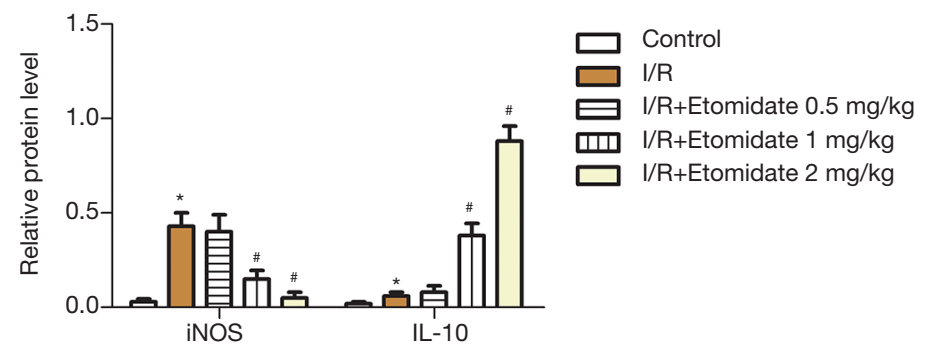

Figure 5 Effects of etomidate on iNOS and IL-10 expression in rat serum and myocardial tissues. (A) Expression of iNOS in rat serum samples; (B) expression of IL-10 in rat serum samples; (C) protein expression of iNOS and IL-10 in rat myocardial samples; (D) protein expression of iNOS and IL-10 in rat myocardial samples were quantified with Inage J. N=6 for each group. *, $\mathrm{P}<0.05$ versus control; , $\mathrm{P}<0.05$ versus $\mathrm{I} / \mathrm{R}$.

\section{Discussion}

Myocardial I/R injury is a common pathology encountered in clinical practice. Here we investigated the protective role of etomidate in rat myocardial I/R injury. After treatment with etomidate for 28 days, echocardiography indexes were restored, a hallmark of reduced myocardial I/R injury. Furthermore, HE staining and cardiac marker enzymes were improved, and fibrosis, oxidative stress and inflammation were also mitigated by etomidate treatment. The results support the protective role of etomidate in 
myocardial I/R injury.

Anesthetics have been shown to ameliorate I/R injury. Etomidate was also reported to inhibit I/R injury through reducing oxidative stress and rebalancing ion transport (5). The inhibition of I/R injury by etomidate has also been implicated in the skeletal muscles (10), brain (11), and lower extremities (12). The mechanism of action for etomidate mainly includes the inhibition of oxidative stress, apoptosis and inflammation. However, like other anesthetics, etomidate failed to show any benefits in a diabetic renal I/R injury rat model (13). In an in vitro model of guinea pig myocardium, etomidate failed to show significant electrophysiological effects (14). The limited effects of etomidate in hyperglycemic individuals might be glucagon-like-peptide-1 (GLP-1) receptor and sodium-glucose cotransporter-2 (SGLT-2) related (15). The limited effects in hyperglycemic individuals may also be the reason that etomidate has generally shown a modest effect in the amelioration of I/R injury compared to other anesthetics in clinic $(6,14)$. Furthermore, the regulation of ion transport, which is usually accompanied by altered electrophysiological effects, is not likely to be an important part of the mechanism of action of etomidate.

In the present study, we showed that treatment with etomidate for 28 days dose dependently alleviated myocardial I/R injury. The targets for etomidate include fibrosis, oxidative stress and inflammation. Fibrosis was characterized as an important indicator of $\mathrm{I} / \mathrm{R}$ injury. Myocardial infarct border zone injected mesenchymal stromal cells (MSC) based therapy is promising therapy for IHD. Overexpression of $\mathrm{N}$-cadherin promoted MSC survival and functioning in I/R mice, which was accompanied by reduced fibrosis (16). Furthermore, inhibition of fibrosis was indicated as part of the mechanism of action for different therapeutics, including apelin and exercise (17), AT1 receptor antagonism (18), and the $\alpha 2$ adrenergic receptor agonist dexmedetomidine (19). In the present study, we showed that fibrosis in I/R rats was dose dependently inhibited with etomidate treatment. However, the relationship between fibrosis and I/R injury remains largely unknown.

Oxidative stress and inflammation have been shown to be involved in both the pathology of I/R injury and the pharmacology of etomidate (20-22). For example, in I/R injury of tibial fracture surgery patients, the use of etomidate for maintaining sedation effectively maintained serum SOD activity and inhibited the release of inflammatory factors (12). The inhibition of inflammation and oxidative stress are also part of the mechanism of some myocardial I/R injury therapeutics such as irbesartan and cathelicidin-related antimicrobial peptide $(18,23)$. Consistent with this, we also showed that both oxidative stress and inflammation were dose dependently inhibited with etomidate treatment in myocardial I/R rats. These results support etomidate usage in preventing myocardial I/R injury.

There are some limitations to this work. Generally, etomidate is used as an anesthetic inducer, and its retention time in vivo is limited (24). Treatment with etomidate once daily for 28 days typically results in limited blood concentration. Hence, it is not possible to confirm that the effects of etomidate were the result of 28-day treatment or etomidate pretreatment. Secondly, the experiment was carried out with more than 6 rats per group, and the rats that did not survive the experiment were not included in the results, which possibly introduced biased. Thirdly, the relationship between the effects of etomidate and underlying mechanisms are still largely unknown. Furthermore, it was reported that etomidate provided no benefit for renal I/R injury in rats under hyperglycemia (13), which challenges the benefit of etomidate especially in myocardial I/R with hyperglycemia. This requires further investigation so that the mechanism of action of etomidate is uncovered. Similar problems also pose a challenge for etomidate-based drug discovery (25).

In conclusion, we showed that etomidate ameliorated myocardial I/R injury in SD rats, possibly through the inhibition of cardiac dysfunction, fibrosis, oxidative stress and inflammation.

\section{Acknowledgments}

Funding: None.

\section{Footnote}

Reporting Checklist: The authors have completed the ARRIVE reporting checklist. Available at http://dx.doi. org/10.21037/atm-20-6015

Data Sharing Statement: Available at http://dx.doi. org/10.21037/atm-20-6015

Conflicts of Interest: All authors have completed the ICMJE uniform disclosure form (available at http://dx.doi. org/10.21037/atm-20-6015). The authors have no conflicts of interest to declare. 
Ethical Statement: The authors are accountable for all aspects of the work in ensuring that questions related to the accuracy or integrity of any part of the work are appropriately investigated and resolved. The animal experimental protocol was approved by the Ethics Committee of Sichuan Academy of Medical Science \& Sichuan Provincial People's Hospital and applied in compliance with Chinese National Guidelines (GB/T 35892-20181).

Open Access Statement: This is an Open Access article distributed in accordance with the Creative Commons Attribution-NonCommercial-NoDerivs 4.0 International License (CC BY-NC-ND 4.0), which permits the noncommercial replication and distribution of the article with the strict proviso that no changes or edits are made and the original work is properly cited (including links to both the formal publication through the relevant DOI and the license). See: https://creativecommons.org/licenses/by-nc-nd/4.0/.

\section{References}

1. Jabbar AY, Baydoun H, Janbain M, et al. Current concepts in the management of stable ischemic heart disease and acute coronary syndrome in patients with hemophilia. Ann Transl Med 2018;6:299.

2. Xia Z, Li H, Irwin MG. Myocardial ischaemia reperfusion injury: the challenge of translating ischaemic and anaesthetic protection from animal models to humans. $\mathrm{Br}$ J Anaesth 2016;117 Suppl 2:ii44-62.

3. Davidson SM, Ferdinandy P, Andreadou I, et al. Multitarget Strategies to Reduce Myocardial Ischemia/ Reperfusion Injury: JACC Review Topic of the Week. J Am Coll Cardiol 2019;73:89-99.

4. Zheng $\mathrm{H}$, Zhu Y, Chen K, et al. The effect of etomidate or propofol on brainstem function during anesthesia induction: a bispectral index-guided study. Drug Des Devel Ther 2019;13:1941-6.

5. Yu Q, Zhou Q, Huang H, et al. Protective effect of etomidate on spinal cord ischemia-reperfusion injury induced by aortic occlusion in rabbits. Ann Vasc Surg 2010;24:225-32.

6. Xu H, Chen S, Luo W, et al. Effect of stress on myocardial apoptosis in ischemic preconditioning in rabbit hearts. Zhong Nan Da Xue Xue Bao Yi Xue Ban 2014;39:477-82.

7. Fliss $\mathrm{H}$, Gattinger D. Apoptosis in ischemic and reperfused rat myocardium. Circ Res 1996;79:949-56.

8. Kim HB, Hong YJ, Park HJ, et al. Effects of Ivabradine on
Left Ventricular Systolic Function and Cardiac Fibrosis in Rat Myocardial Ischemia-Reperfusion Model. Chonnam Med J 2018;54:167-72.

9. Zhao Z, Liu M, Zhang Y, et al. Cardioprotective Effect of Monoammonium Glycyrrhizinate Injection Against Myocardial Ischemic Injury in vivo and in vitro: Involvement of Inhibiting Oxidative Stress and Regulating $\mathrm{Ca}(2+)$ Homeostasis by L-Type Calcium Channels. Drug Des Devel Ther 2020;14:331-46.

10. Ergun $Y$, Oksuz H, Atli Y, et al. Ischemia-reperfusion injury in skeletal muscle: comparison of the effects of subanesthetic doses of ketamine, propofol, and etomidate. J Surg Res 2010;159:e1-10.

11. Harman F, Hasturk AE, Yaman M, et al. Neuroprotective effects of propofol, thiopental, etomidate, and midazolam in fetal rat brain in ischemia-reperfusion model. Childs Nerv Syst 2012;28:1055-62.

12. Li R, Fan L, Ma F, et al. Effect of etomidate on the oxidative stress response and levels of inflammatory factors from ischemia-reperfusion injury after tibial fracture surgery. Exp Ther Med 2017;13:971-5.

13. Yoo YC, Yoo KJ, Lim BJ, et al. Propofol attenuates renal ischemia-reperfusion injury aggravated by hyperglycemia. J Surg Res 2013;183:783-91.

14. Hanouz JL, Repesse Y, Zhu L, et al. The electrophysiological effects of racemic ketamine and etomidate in an in vitro model of "border zone" between normal and ischemic/reperfused guinea pig myocardium. Anesth Analg 2008;106:365-70, table of contents.

15. Sharma A, Verma S. Mechanisms by Which GlucagonLike-Peptide-1 Receptor Agonists and Sodium-Glucose Cotransporter-2 Inhibitors Reduce Cardiovascular Risk in Adults With Type 2 Diabetes Mellitus. Can J Diabetes 2020;44:93-102.

16. Yan W, Lin C, Guo Y, et al. N-Cadherin Overexpression Mobilizes the Protective Effects of Mesenchymal Stromal Cells Against Ischemic Heart Injury Through A BetaCatenin Dependent Manner. Circ Res 2020;126:857-74.

17. Nazari A, Chehelcheraghi F. Using Apelin and exercise to protect the cardiac cells: synergic effect in ischemia reperfusion injuries treatment in rats. Bratisl Lek Listy 2020;121:14-21.

18. Ramalingam A, Budin SB, Mohd Fauzi N, et al. Angiotensin II Type I Receptor Antagonism Attenuates Nicotine-Induced Cardiac Remodeling, Dysfunction, and Aggravation of Myocardial Ischemia-Reperfusion Injury in Rats. Front Pharmacol 2019;10:1493.

19. Zhou J, Yuan-yuan Jiang, Chen H, et al. Tanshinone 
I attenuates the malignant biological properties of ovarian cancer by inducing apoptosis and autophagy via the inactivation of $\mathrm{PI} 3 \mathrm{~K} / \mathrm{AK} T / \mathrm{m}$ TOR pathway. Cell Proliferation 2020;53(2).

20. Toldo S, Mauro AG, Cutter Z, et al. Inflammasome, pyroptosis, and cytokines in myocardial ischemiareperfusion injury. Am J Physiol Heart Circ Physiol 2018;315:H1553-68.

21. Gonzalez-Montero J, Brito R, Gajardo AI, et al. Myocardial reperfusion injury and oxidative stress: Therapeutic opportunities. World J Cardiol 2018;10:74-86.

22. Yue Y, Huang S, Wang L, et al. M2b Macrophages Regulate Cardiac Fibroblast Activation and Alleviate Cardiac Fibrosis After Reperfusion Injury. Circ J

Cite this article as: Xie D, Li M, Yu K, Lu H, Chen Y. Etomidate alleviates cardiac dysfunction, fibrosis and oxidative stress in rats with myocardial ischemic reperfusion injury. Ann Transl Med 2020;8(18):1181. doi: 10.21037/atm-20-6015
2020;84:626-35.

23. Wang X, Chen L, Zhao X, et al. A cathelicidin-related antimicrobial peptide suppresses cardiac hypertrophy induced by pressure overload by regulating IGFR1/PI3K/ AKT and TLR9/AMPKalpha. Cell Death Dis 2020;11:96.

24. Shen Y, Cai MH, Ji W, et al. Unrepaired Tetralogy of Fallot-related Pathophysiologic Changes Reduce Systemic Clearance of Etomidate in Children. Anesth Analg 2016;123:722-30.

25. Wang B, Jiang J, Yang J, et al. Pharmacologic studies on ET-26 hydrochloride in a rat model of lipopolysaccharideinduced sepsis. Eur J Pharm Sci 2017;109:441-5.

(English Language Editor: C. Betlazar-Maseh) 